to say that it is nerve alone that feels; but, as our sensations are as various as our organs, it is the best plan to speak as if they were in reality the seats of pain, etc. Take for example a condylomatous growth and a cancer: we cannot suppose that new nerves are formed in them; for, however much we may be lieve in possible nerve-extension in the part itself, we cannot suppose that an extension of the new fibrils takes place all the way along the nervous trunks into the brain, which is necessary before a new growth can be sensitive. Yet, notwithstanding the presumed absence of nervous fibrils in the new growths, the former is generally more sensitive than the healthy skin, and the latter has sensations peculiar to itself.

I consider, then, that it is far better to attribute the causes of pain to some modification of the organs to which the sensa tion is referred, than to enunciate that all pain, etc., is only "nervous irritation", and that it is the function of the sentient nerves to report to the sensorium the condition of the parts from which they come, rather than for themselves to originate the state of things on which the pain depends.

Another objection to the explanation I have attempted of the so called hysterical pains, is one that is deeply ingrained in the mind of the majority of medical men, viz., that these pains are not real-that they are severe and unbearable only because the patients allow their mind to dwell upon them. To believe this is to believe that an individual can create a pain, and, by parity of reasoning, can destroy one; that thinking long of a tooth can produce toothache; and that an intense abstraction of minc may destroy the pains of gout or uterine contraction! I have long been at a loss to know by what warrant the physician asserts that a pain his patient feels has no real existence; and, after long searching out the cause, can only attribute the presumption to that loose style of reasoning so lamentably common in the profession. It is taken as an axiom, that hysterical patients are fond of sympathy; that the sufferings they experience are exaggerated when real; and therefore that, whenever they complain of a symptom which the doctor can see no reason for it must be a false creation-an hysterical symptom, and of $n$ consequence-just a "Pickwickian" insult to the nerves! I have myself suffered from that very cutaneous tenderness, etc. which I have described; and I have had male acquaintance who have themselves experienced pains precisely similar to those complained of by hysterical females. All describe them nearly in the same terms. The seats of pain are the same in both sexes ; in both, the sensation is compared to a "wearing", hot, or burning pain. In all cases, there has been unusual excrtion of the abdominal muscles, either in walking, rumning, jumping, laughing, hauling on ropes, ringing heavy bells, etc. The pains have been located in the very regions in which we find the so called hysterical pain most common, $i . e$., in the attachments of the obliquus externus and rectus abdominis, or in the fleshy parts of the same muscles. In all, the pain. might have been said to have been hysterical, had they occurred in young women.

I must now answer the oljection, that young women do nothing to fatigue their abdominal muscles; and, consequently that the idea of their pains arising from over-fatigue is absuri I distinctly say, that the individuals in whom the hysterical pains about the abdomen are so common do habitually fatigue their muscles to a very great extent.

Let us bear in mind, in the first place, that what is only ordinary work for a healthy person, when his muscles are strong, becomes excessive when those muscles are reduced in power; and that, if soreness, tenderness, and pain, resul from double work in a strong man, the same results will follow from common work when the strength has been reduced onehalf. But as we know that precisely similar causes will produce greater suffering in any individual when there is great debility than when there is full health, so there is reason to believe that the pain from over exertion in a weak muscle is more than proportionately severe to what it would be if the muscle were in a healthy state, and that the weaker and weaker the muscle is, the more doubly intense will be the suffering Insufficient diet, loss of appetite, of blood, or of rest; excessive discharges, whether catamenial or leucorrhon! ex cessive diarrhœa, the results of fevers, incipient and confirmed phthisis, profuse perspirations, indigestion, and the like, all have a direct tendency to reduce the muscular power.

If, then, with reduction of power, the amount of work done remains the same, what can the muscles do but complain, as did the Israelites in Egypt, when they had to deliver the same tale of bricks, with an arrested supply of material

A healthy school-girl can sit erect, sew, knit, do rug-work, play for hours at the piano, and then end the day with many an hour's dancing; and only feel fatigue. But if she have menorrhagia, or any other thing to diminish her strength, the very same exertion will be, for her then condition, excessive and productive of pain. It is generally under these or similar circumstances that we think we are certain to recognise hysterical symptoms. Many a strong well fed man will suffer severe abdominal and dorsal pain, if he have to sit or stand for many hours without any rest for his head, his elbows, or his arms; yet we think a poor ill fed sempstress, who sits sewing, supporting her head at a great disadvantage, using both shoulders incessantly for eighteen hours a day, is guilty of shamming or hysteria, if the labour is ultimately too great for the trapezius and abdominal muscles, and is followed by pain and soreness ! Few of us, indeed, ever cast a thought upon the avocations of women, or the amazing amount of physical exertion they undergo during the twenty-four hours, and often with gradually failing health. The mother of a family may get on well enough till she is pulled down by over-nursing; she still does her work, but it pains her; she becomes sore, tender, miserable; she sends at last for the doctor, and has the delight of hearing that her sufferings are only hysterical or nervous! She says to herself, and sometimes, too, to the physician, " $\mathrm{Ah}$, if you felt my pains, you would think more of them; you would never say, "Oh, they are of no consequence." And she is right. If the doctor really felt them, he would at once recognise their cause, and, by simply giving strengthening remedies and directing more rest and less work, he would cure them speedily.

I have known, in delicate or phthisical patients, " hysterical " pain produced by prolonged sitting, practising at the piano, travelling, walking, carriage exercise on indifferent roads, dancing, laughing, rug-work, coughing, straining at stool; from an energetic discharge of the common household duties; from washing, ironing, mangling, sewing, dusting furniture, shaking carpets, etc. When once present, it is kept up by turning in bed, coughing, defacation, urination, talking, sneezing, and the like.

Now, bearing these things in mind, we can readily understand why the plans adopted for the relief of hysterical pains may have made them worse. Increased food, tonics, and diminished labour, have been the things demanded; but the doctor has used, with the best intentions, aperients, blisters, leeches, and low diet; and no attention whatever has been given either to assist the fatigued muscles, or relieve them of their work. No wonder that, under the circumstances, the patients find themselves worse and worse. How can they be otherwise, when, their work remaining ever the same, the doctor is constantly diminishing their power to do it? No wonder that at last the diminution of strength is so excessive that the individual is obliged $t$, lie up. When that result has been attained, the muscular system is so excitable that even ordinary respiration is a burden, and any active motion of the body almost unbearable. Nor ought there to be any surprise, we may add, that the patient should begin to recover under homœopathy-a system which supports the strength, and never pulls it down by medicines.

I can only add, that I have put the ideas enunciated above to the test of two years experience; and that $I$ have most serious doubts whether the idea of "hysterical pain", as contradistinguished from pains common to all ages and sexes, ought not to be expunged entirely from all our medical writings. The symptom referred to has been a traitor to lure us astray: it ought to be expelled from our camp.

\section{DIPHTHERITIC CONJUNCTIVITIS: A SYMPTOM OF OPHTHALMITIS.}

By Williaj Mackenzie, M.D., Surgeon-Oculist in Scotland in Ordinary to the Queen.

BEFORE attempting to establish a new genus or species of disease, the careful pathologist makes it his business to discover whether what he purposes to discriminate from other diseases has not been already described by his predecessors, and thus enables himself to avoid imposing merely a new name upon what was essentially known before.

In a paper by Mr. Prichard (British Megical Journal, Nov. $28,185 \%$, p. 981 ), entitled "Diphtheritic Conjunctivitis", that gentleman enumerates various authors, in whose writings he had not found any description of the pathological state to which that name has been applied; and among them he mentions me. The cases of destructive inflammation of the eyes, related by $\mathrm{Mr}$. Prichard in the paper referred to, followed scarlatina, and are well worthy of being recorded. 
The name "Diphtheritic Conjunctivitis", first used by Dr. Von Gräfe, of Berlin (Archiv für Ophthalmologie, Band i, Abtheil I, p. 168. Berlin. 1854), being a new one, does not occur in my Practical Treatise on Diseases of the Eye; yet I have both seen and recorded the fact, that ophthalmitis is, in certain cases, attended by a lymphatic exudation, and the formation of a false membrane, on the conjunctiva. I have also enumerated scarlatina, along with other blood-diseases, as apt to be followed by ophthalmitis. Two short quotations will serve to establish this statement. After mentioning that there are differences in the progress of ophthalmitis, and in the order in which the symptoms follow one another, I go on to say-

"The conjunctiva continues to swell; and what does not occur except in cases of ophthalmitis, this membrane, especially where it lines the lower eyelid, becomes covered with a layer of coagulable lymph, which may be detached like a false membrane, and which is gradually reproduced. This appearance is observed in idiopathic, traumatic, and phlebitic cases of ophthalmitis, and serves to show the analogy which exists between these three varieties of the disease." (Practical Treatise, 4th Edit., p. 585. London: J 854.)*

"The causes of idiopathic ophthalmitis ..... are often obscure; slight injuries, such as a simple puncture, may produce the disease in some particular states of the constitution. There is reason to believe that ophthalmitis occurs as a consequence of certain eruptive fevers, such as measles, small pox, scarlatina, and typhus. Whether in these cases the dis ease arises from pus being taken up by the veins from some of the viscera, can at present be merely proposed as a query." (Ib., p. 587.)

Ten years ago, M. Chassaignac announced, that the conjunctiva was covered in ophthalmia neonatorum by a pseudo membrane, and that a great improvement in the treatment of that disease consisted in the employment of a cold water douche to the eyes. (Annales d'Oculistique, tome xviii, pp. $138,140,273,279$. Bruxelles: 1847.) There is reason, however, to suspect that what he regarded as a false membrane was not a mere exudation, but rather the epithelium, so thickened and changed by the inflammation, and the action of the douche, that it could be detached by the forceps. If so, ophthalmia neonatorum is not, as $\mathbf{M}$. Chassaignac considered it, an " ophthalmie diphthéritique pseudo-membraneuse."

Beclard, speaking of the inflammatory affections of mucous membranes, says -

" L' inflammation couenneuse ou plastique y est moins fréquente. Cependant on l'observe fréquemment dans les voies aériennes où elle constitute le croup, et assez souvent dans les voies alimentaires, dans les intestins, la vessie, l'urètre, et même quelquefois aux yeux." (Elémens d'Anatomie Générale, p. 243. Paris : 1827.)

In his Additions to Bichat, he states that the conjunctiva, when inflamed in consequence of exposure to the vapour of hydrochloric acid, presents a covering of false membrane. (Additions d l'Anatomie Générale, p. 233. Paris : 1821.)

Such a fact (unless the swollen and softened state which the conjunctiva assumes when acted on by a strong mineral acid, has been confounded with a lymphatic exudation on its surface), may be conceded as affording an example of a pseudomembranous or diphtheritic conjunctivitis; but in no other instance with which $I$ am acquainted is an effusion of coagulable lymph on the surface of the conjunctiva, forming a layer, which can be peeled off like a pellicle or skin $(\delta, \phi \theta \in \dot{\rho} \rho)$, part of any mere conjunctivitis. Such an exudation, however, I am conversant with as an occasional attendant on that severe form of general inflammation of the eyeball and orbital tissues, to which the name of ophthalmitis is applied.

This inflammatory affection of the whole contents of the orbit arises from a variety of causes :

1. It arises, although rarely, from injuries of the eye. I have known it to follow an operation for cataract.

2 . It is sometimes regarded as idiopathic, being seemingly produced by cold or some such influence, as in an interesting case by Bouisson, in which the pseudo-membranous formation on the conjunctiva was very remarkable. (Annales d'Oculistique, tome xvii, p. 100. Bruxelles: 1847.)

* In the 3rd edition (1840), the fact of lymphatic exudation in ophthalmitis is noticed at p. 513. Also, in Notes of a Lecture, etc. (Medical Gazette, Fobruary 7 th, 1\&45, p. 594.)

Mr. Wharton Jones, at p. 61 of his " Principles and Practice of Ophthalmic Medicine and Surgery," 2nd edition (1855), has a paragraph on pseudomembranous exudation on the conjunctiva. A similar paragraph will b the Eye. (British and Foreign Medical Review, July 1845, p. 276 .)
3. One of its most frequent causes is purulent infection of the blood, in consequence of erysipelas or diffuse cellular in. flammation, or of traumatic or uterine phlebitis.

4. It is an occasional sequela of certain fevers, as typhus, measles, valiola, and scarlatina.

5. Recent observations show that a congener of scarlatina, = viz., croupy sore-throat or diphtheritis, sometimes leads to ophthalmitis.

When ophthalmitis arises from any of these causes, we find the eyeball protruded from the orbit, and apparently enlarged; the eyelids swollen, stretched, everted and hard; the conjunc tiva and subjacent areolar tissue affected with white or serous chemosis, a state easily distinguished from common chemosis, inasmuch as it is attended with scarcely any increase of vascularity; while on the surface of the conjunctiva there is deposited, although not in all cases, a layer of coagulated lymph, which, if stripped off, is formed again and again. At last the conjunctiva does become red, and, ceasing to exude lymph, gives out puriform mucus. It often happens, in this terrible disease, that both eyes are involved; that vision is rapidly extinguished; that the aqueous chambers are seen to be the seat of bloody, lymphatic, or puro-lymphatic effusion; that the cornea grows dim, and either it or the sclerotica ulcerating and giving way, the contents of the eyeball are partly evacuated, unless, indeed, the patient has already shown signs of meningitis, followed by coma, and the case has ended fatally.

On dissection, the great hardness and swelling of the orbital tissues, which existed before death, are found much reduced; the ocular capsule and surrounding cellular substance infiltrated with sero-purulent fluid; sometimes one or several small but distinct abscesses within the orbit; the eyeball, which, during life, had seemed enlarged, of its natural size; lymphatic or purulent deposition between the choroid and the retina, and within the vitreous humour; the ophthalmic veins, cavernous sinus, and occasionally some of the cerebral veins inflamed, and obstructed with inflammatory products. (Practical Treatise, 4th Edit., Cases 281, 292. pp. 586, 593. Bowman's Lectures, Cases M, N. pp. 123, 12\%. London: 1849. Desmarres Maladies des Yeux, 2nd Edit., tome ii, p. 222. Paris: 1855 . Poland, Ophthalmic Hospital Reports, Oct., 1857, p. 30.)

It is plain that the inflammation of the mucous covering of the eye is not, in such cases, the origo mali-not the material part of the disorder, but only an adjunct. The diphtheritic exudation is not the starting point of the disease, nor the circumstance which determines its progress, nor causes the chief danger, nor indicates the treatment. It is the pressure of the infiltrated orbital tissues, and the inflammatory condition of the internal structures of the eye, and of the veins arising from it, which prove destructive to vision or to life.

An occurrence, then, which is not constant, but which only occasionally attends the general inflammation of the eyebal and orbital tissues, arising from the causes already enumerated, cannot, I maintain, be taken as the basis of a specific distinction; and therefore I object to the terms "ophthalmie pseudomembraneuse" of Professor Bouisson, and "conjunctivitis diphtheritica" of Dr. Von Gräfe and Mr. Prichard.

The diphtheritic affection of the conjunctiva is not a distinct disease, but only a symptom, and that far from an important one, in the circumstances described. It is a symptom which marks, no doubt, the peculiarity, as well as the violence, of the inflammatory process going on in the subconjunctival structures, and is therefore not to be overlooked; but it is in itself of no importance, so far as the treatment of the formidable affection of the eye is concerned; on the contrary, if promi. nently brought into view, and treated as a separate disease, it might altogether deceive the practitioner, leading him to apply remedies to the surface of the eye, such as solution of nitrate of silver, which could be of no use, while he neglected those likely to subdue the essential and deep-seated disease, which, in spite of any application to the conjunctiva, might be hastening on to disorganise the organ of vision, and even to destroy life.

The causes of ophthalmitis, with diphtheritic exudation, already enumerated, appear, at first sight, very different; for we have, first, injuries; secondly, exposure to changes of temperature; and, thirdly, blood-diseases. The symptorns, however, which occur when the disease springs from the first or $\sigma$ second of these classes of causes, so strongly resemble those which attend it when produced by the operation of the third 8 class, that it naturally suggests itself, whether in those subjects in whom a wound of the eye or exposure to cold is followed by ophthalmitis, a morbid condition of the blood-a blood over. charged, perhaps, with one or other of its constituent prin.? 
ciples, or carrying with it some contamination, which has either been generated within the body, or received into it from without -is not already present. It is well known that the period when local diseases, undoubtedly of constitutional origin, arise, is very different in different persons and different constitutions, and that in many instances the constitutional affection long remains smouldering and unheeded, till some external cause, perhaps one which would have proven a trifle in ordinary circumstances, serves to excite a local disturbance of the most formidable description-so formidable, indeed, that the signs of a constitutional or blood-disease are probably lost to the eye of the practitioner in those of the secondary and local affection.

We have no hesitation, when phlebitis gives rise to ophthalmitis, in saying, that pus.cells, being taken up from the inflamed vein and circulating with the blood, are arrested in the capillaries of the eyeball, and give rise to inflammation of the choroid and iris, secondary abscess in the vitreous and aqueous cells, inflammation of the ophthalmic veins, and a sympathetic affection of the orbital tissues, including the conjunctiva.

In Mr. Prichard's cases, we hesitate as little in concluding, that by absorption of the scarlatinous virus into the blood, and by ulterior changes in this fluid, the local disease of the eye is produced.

When we meet with ophthalmitis, then, showing itself suddenly, after some trifling wound, or without any prominen exciting cause, our suspicion should be roused, that so serious and so rare a local affection may depend on a contaminated state of the blood; or, at any rate, that ocular phlebitis has almost certainly ensued.

Such a series of cases as Mr. Prichard narrates seems, at first sight, to support Dr. Von Gräfe's idea, that the diph theritic affection of the eye is in itself contagious. I do not believe that it is really so, but only that such an exciting cause as scarlatina or variola, being propagated from person to person, may give rise to a succession of cases of inflammatory destruction of the eye. Dr. Von Gräfe's dread of the one eye inoculating the other with diphtheritic inflammation I regard as equally groundless.

\section{CASE OF HYDROCEPHALOID DISEASE.}

By Charies Wilitam Graham, M.D., late Surgeon, Edinburgh Regiment of Militia.

Near eleven o'clock on the night of March 26th, 1841, I was urgently requested to visit a little girl of Mr. M.'s, two years and a half old. She had been under the charge of a medical gentleman here for the two previous days, so that $I$ did not exactly learn what treatment she had received, except that some doses of calomel, and several domestic enemata, had been administered.

On examination, I found that the child had no pain on pres sure being applied to the region of the stomach and bowels, though there was the most urgent desire for cold water, which was immediately rejected. The skin was cool; the pulse 88 , soft, and moderately full; the tongue thickly coated to the point, and red round the edges. The bowels were confined there was constant picking at the nose and angles of the mouth; and the child awoke suddenly screaming from short sleeps; the countenance was occasionally flushed; the urine was high coloured and scanty. I recommended the application of a sinapism, for half an hour, over the region of the stomach, thereafter a small tablespoonful of castor oil, and to be repeated if the bowels were not relieved.

March 27th, 8 a.r. The symptoms continued as at last night's visit, with the addition of strabismus, dilatation of the pupils, grinding of the teeth; the pulse was small, and very feeble; the face pale and collapsed. The child had suffered two or three convulsive seizures. She had passed two darkcoloured, offensive evacuations after the second dose of oil; but the stomach still continued very irritable, with great thirst. gave her a teaspoonful of sherry in the form of negus, and ordered a blister to the region of the stomach, the extremitie to be wrapt in warm flannel, and to have every hour and a half eight drops of the compound spirits of ammonia, alternated with twenty drops of brandy in arrowroot. Absolute rest was enjoined, and orders were given that the child should on no account be raised into the erect posture. At noon, the con vulsions had greatly increased in violence and frequency, and were of longer duration, with constant tossing of the arms, and general restlessness. Two drachms of assafoetida were directed to be dissolved in eight ounces of boiling water; and, after being strained, half of this solution was thrown into the bowels. This acted like a charm, for the fits ceased immediately, and never returned; vomiting also ceased. The ammonia and brandy in arrowroot were continued.

5 P.M. The symptoms continued as at last visit; the pulse was 124 , small and feeble; the surface warm; the breathing occasionally stertorous and suspended.

9 P.M. The was no alteration. Three drops of laudanum were directed to be given every six hours along with the brandy and ammonia.

March 28th, 8 A.s. She had passed rather a good night. I got her, with some difficulty, to show me her tongue, which was very red, and somewhat fiery; the thirst was abated; but there was continual tossing of the arms; the eyes were half closed and turned up; the pupils contractile; pulse 118, soft and rather full; the bowels not opened since yesterday; and the urine was passed in bed. The blister had risen well. Directions were given to continue the ammonia and brandy, increasing the dose to ten drops of the former and thirty of the latter; and to discontinue the laudanum.

1 P.sr. There was no change in the symptoms. The treat. ment was continued.

9 p.r. The symptoms had become greatly aggravated since last visit. She had all the appearance of sinking fast; the extremities becoming cold, as well as the nose and cheeks; she was still able to swallow. The brandy, etc., were ordered to be given more frequently, and warmth applied to the limbs. I returned at 11 P.M., and remained during the night.

March 29th, 2 A.r. My little patient lay in a comatose state, from which I could not rouse her; the powers of deglutition seemed to be nearly gone, as the arrowroot and brandy ran from the mouth. I sent for the following mixture: Compound spirit of ammonia $\xi_{i}$; croton oil 50 drops. With this liniment the nape of the neck and back part of the head were well rubbed for ten minutes. Shortly after she began to complain of pain, and frequently applied her hand to the part that was rubbed with the embrocation. I got her now to swallow a little arrowroot and brandy; afterwards she fell into the same dozing state for four hours, when she was again rubbed, and had some nourishment given her.

7 A.s. She seemed more sensible than I had seen her for the last two days; squinting continued, however, along with dilatation of the pupils. The pulse was 106, more full, and improving in strength. Two drachms of castor oil were ordered to be given in beef.tea, and the ammonia, etc., at in tervals of four hours.

10 A.M. The howels had acted well; the eracuations were copious, dark, and offensive.

2 P.M. The strabismus was gradually going off, and the eyes and countenance were assuming their natural appearance.

9 P.M. The pulse was 96 , becoming stronger; she had had another alvine evacuation, neither so dark nor so offensive. She took the beef-tea readily. The brandy and ammonia were discontinued.

March 30th. She passed a good night; the squinting was completely gone; the features were more expanded, and the countenance was cheerful and lively; the tongue was very fiery; the appetite rather keen, and she was continually calling for bread. Two drachms of castor oil were given; and the beef-tea was continued. From this date my little patient, by strict attention to the bowels, and mild nutritious food, progressively improved, and was soon restored to her wonted health.

REMARKs. I could adduce many similar cases of this very singular morbid affection; but suffice it to say, that they were all subjected to the same treatment as the one now recorded and attended with equal, though unlooked-for, success.

To the writings of Drs. Ahercrombie, Marshall Hall, and Gooch, and the work of Drs. Evanson and Maunsell, I certainly feel much indebted for the knowledge I have obtained of this disease. The similitude of this affection to hydrocephalus verus is so great, and so strongly marked, that it may be very readily mistaken for, and treated as such by the general practitioner; and this is one of the chief reasons that induces me at present to direct attention to a subject which, there is reason to believe, is not very generally understood.

It is a fact which cannot be denied, and should ever be borne in mind, that there are diseases which, while they have a great resemblance to each other, arise from the most opposite causes; and it is not to be wondered at, therefore, that the brain should become affected in a manner so remarkably similar, from the two opposite states of overfulness and of deficiency of blood. 